\title{
Regímenes de política social en América Latina: una revisión crítica de la literatura*
}

FLORENCIA ANTÍA**

Artículo recibido: 12 de abril de 2016

Artículo aceptado: 14 de septiembre de 2017

Doi: http://dx.doi.org/10.12804/revistas.urosario.edu.co/desafios/a.4802

Para citar este artículo: Antía, F. (2018). Regímenes de política social en América Latina: una revisión crítica de la literatura. Desafios, 30(2), 193-235. Doi: http://dx.doi.org/10.12804/ revistas.urosario.edu.co/desafios/a.4802

\section{Resumen}

El articulo analiza los principales aportes de la literatura académica acerca de los regímenes de políticas sociales que se configuraron en los países latinoamericanos desde inicios del siglo XX hasta la actualidad. Se concentra en la variación en los regímenes depoliticas sociales a nivel intrarregional, a lo largo del tiempo, así como en los factores políticos que explican esos resultados. Tras la identificación de tres etapas en el desarrollo de las politicas sociales, el estudio destaca los desafíos que boy en dia se plantean en materia de protección social, los principales aportes y vacios en la literatura, así como asuntos a profundizar en una futura agenda de investigación.

Palabras clave: regímenes de políticas sociales, protección social, América Latina.

\footnotetext{
* Agradezco a los árbitros anónimos que evaluaron este escrito por sus comentarios y recomendaciones.

** Doctora en Ciencia Política, Instituto de Estudos Sociais e Políticos, Universidade Estadual de Rio de Janeiro (IESP-UERJ), Brasil. Profesora Adjunta Grado 3, Instituto de Ciencia Política, Facultad de Ciencias Sociales, Universidad de la República, Uruguay. Correo electrónico: florenciaantia@gmail.com. ORCID: http://orcid.org/0000-0001-5421-8476
} 


\title{
Social Policy Regimes in Latin America: A Critical Review of the Literature
}

\begin{abstract}
The article discusses the main academic contributions to the study of different social policy regimes in Latin America since the beginning of the 20 th century to the present time. It analyzes social policy regime variation across countries and time, as well as the politics of social policy during this period. After identifying three stages in the development of social policies, the article highlights the main challenges of Latin America's social protection regimes, the main contributions and gaps in the literature, as well as the issues that should be considered in a future research agenda.
\end{abstract} Keywords: social policy regime, social protection, Latin America.

\section{Regimes de política social na América Latina: uma revisão crítica da literatura}

\begin{abstract}
Resumo
$O$ artigo analisa os principais aportes da literatura acadêmica acerca dos regimes de politicas sociais que se configuraram nos países latino-americanos desde inícios do século $X X$ até a atualidade. Concentra-se na variação nos regimes de políticas sociais no nível intrarregional e ao longo do tempo, assim como nos fatores politicos que explicam esses resultados. Após a identificação de três etapas no desenvolvimento das políticas sociais, o estudo destaca os desafios que atualmente se apresentam em matéria de proteção social, os principais aportes e vazios na literatura, assim como assuntos a aprofundar em uma futura agenda de pesquisa.
\end{abstract}

Palavras-chave: regimes de politicas sociais, proteção social, América Latina.

\section{Introducción}

Luego de más de una década de crecimiento económico, América Latina presenta un panorama social complejo. La pobreza afecta a casi uno de cada tres ciudadanos (CEPAL, 2016, p. 19), al tiempo que la región tiene el mayor nivel de desigualdad económica del mundo 
(CEPAL, 2008, p. 117). Mientras algunos segmentos minoritarios de la población experimentan niveles de bienestar similares a los países desarrollados, la mayoría vive en un contexto de carencias en términos de acceso a recursos económicos y a modalidades de protección social adecuadas. No obstante, la región ingresó en la década de dos mil a una etapa de múltiples reformas en sus políticas sociales que generaron expectativas sobre la posibilidad de avanzar en la construcción de una ciudadanía social más inclusiva (Filgueira, 2013).

El presente artículo realiza una revisión de la literatura sobre las políticas sociales en América Latina, considerando un conjunto amplio de estudios que analizan las principales etapas del desarrollo de los regímenes de políticas sociales. Aun cuando la discusión sobre estos asuntos es menos profusa que la que refiere a los países desarrollados, existe una acumulación de estudios que han realizado aportes relevantes en términos de definición conceptual e identificación de tipos y de etapas de desarrollo de las políticas sociales en la región. Asimismo, varias investigaciones se han preocupado por analizar la dinámica política y económica que guió la conformación de distintos regímenes de políticas sociales entre países y a lo largo del tiempo.

Las contribuciones de este artículo se pueden clasificar en cuatro tipos. Primero, presenta una caracterización sintética de la orientación y de los cambios producidos en las políticas sociales y en los regímenes de políticas sociales en los países de la región. Segundo, sistematiza y articula dos vertientes de la literatura que muchas veces corren por carriles paralelos: la que se refiere a las orientaciones de los regímenes de políticas sociales y la que lo hace a la economía política que condicionó su origen y transformaciones durante buena parte del siglo Xx e inicios del XxI. Tercero, identifica las condiciones causales que están en la base del cambio institucional y del mantenimiento de los regímenes de políticas sociales en los países de la región. Finalmente, realiza un análisis crítico de la literatura, identificando los énfasis existentes y los puntos de controversia, así como los vacíos de mayor relevancia. 
Luego de esta introducción, la primera sección hace una breve reseña de las principales referencias conceptuales para el estudio de los Estados de bienestar a nivel comparado. La segunda sección define a los regímenes de políticas sociales como el objeto de la presente revisión. Las tres secciones siguientes analizan la literatura que recorre las principales fases por las que han atravesado los regímenes de políticas sociales y la dinámica política que los condicionó: la tercera parte considera los estudios que se centran en la etapa de construcción y consolidación a mediados del siglo $\mathrm{xx}$; la cuarta parte analiza la que se enfoca en las tendencias de reforma neoliberal iniciadas en la década de los ochenta; y, finalmente, la quinta sección explora la acumulación académica relativa a la fase de reformas expansivas desplegadas a inicios del nuevo siglo. El artículo concluye con una síntesis de las tendencias identificadas en materia de protección social en la región y de las principales contribuciones, así como asuntos no suficientemente abordados en la literatura.

\section{Principales enfoques sobre el Estado y el régimen de bienestar}

La literatura sobre los Estados de bienestar es sumamente amplia, en particular la que se enfoca en los países desarrollados. Briggs (2006) plantea una definición concisa que sintetiza los principales atributos de lo que en la actualidad se conoce como Estado de bienestar. Se trata de aquel Estado en que:

[...] el poder organizado es utilizado de forma deliberada [...] en un esfuerzo por modificar el juego de las fuerzas de mercado en al menos tres direcciones - primero, al garantizar a los individuos y familias un ingreso mínimo que no guarda relación con el valor de mercado de su trabajo o propiedad; segundo, al reducir la inseguridad permitiendo que individuos y familias resuelvan ciertas "contingencias sociales" (por ejemplo, enfermedad, edad avanzada y desempleo) que conducirían, de otra manera, a crisis individuales y familiares; y tercero, al asegurar que todos los ciudadanos sin distinción de estatus o clase reciban un conjunto de servicios sociales con una calidad que refleje los mejores estándares disponibles_-(Briggs, 2006, p. 16; traducción propia). 
Mientras los primeros estudios que analizaban los Estados de bienestar lo hacían a partir de los niveles de gasto social (Wilensky, 1975), más adelante, la discusión se complejizó, centrándose en el carácter de los regímenes de bienestar y sus impactos sobre la estructura social y el mercado de trabajo. En tal sentido, en línea con el estudio pionero de Titmuss (1958), una de las mayores contribuciones en la materia fue realizada por Esping-Andersen (1990) en el clásico Tres mundos del capitalismo de bienestar. Este último — que estableció los términos de los estudios comparados en ese campo_ ofrece una tipología de distintos “regímenes de bienestar" en las democracias de los países avanzados en las décadas de los setenta y los ochenta. Distingue así entre regímenes liberales, socialdemócratas y corporativos que se diferencian en los alcances de la desmercantilización, los impactos en términos de estratificación social, así como por la forma en que el Estado, el mercado y las familias interactúan en la provisión de bienestar.

Según dicha tipología, el modelo de bienestar liberal presenta un carácter residual en la medida en que las garantías sociales se limitan a los "riesgos inaceptables". El Estado interviene a través de políticas asistenciales, en aquellas circunstancias en las que el mercado falla. Asimismo, se caracteriza por fomentar el mercado como proveedor principal de bienestar. En este tipo se clasifican Estados Unidos, Gran Bretaña, Irlanda, Australia y Nueva Zelanda (Esping-Andersen, 2000, pp. 103-106). En el otro extremo, el régimen socialdemócrata se caracteriza por el universalismo y por un compromiso con la cobertura de riesgos globales a través de subsidios generosos. Los derechos se basan en la ciudadanía antes que en una necesidad demostrada o en una relación laboral. En esta categoría se encuentran Suecia, Dinamarca, Noruega y Finlandia, países que cuentan con los Estados de bienestar más extendidos y generosos (Esping-Andersen, 2000, pp. 106-111). Por último, el régimen corporativo-conservador se sustenta en una mezcla de segmentación de estatus y familiarismo. Las distinciones de estatus corporativas dominan la seguridad social, al tiempo que el familiarismo se manifiesta en una protección social sesgada a favor del varón cabeza de familia y en el carácter central de la familia como dispensadora de cuidados. Reforzando esta pauta, el componente residual se dirige a los "fallos" de la familia. Ejemplos 
de este grupo son Alemania, Italia, Francia y otros países de Europa continental (Esping-Andersen, 2000, pp. 111-114).

Esta tipología se ha constituido en una referencia ineludible para los estudios de regímenes de bienestar. De hecho, el esfuerzo por identificar distintos regímenes de bienestar social se ha convertido en una estrategia de análisis extendida. El enfoque se ha replicado para analizar otras regiones, tales como Europa del Sur (Ferrera, 1996; Moreno, 2002), del Este y el Sur de Asia (Gough, 2000; Holliday, 2000) o América Latina (Gough \& Wood, 2004; Barrientos, 2004; Martínez Franzoni, 2008).

En efecto, Gough y Wood (2004) retomaron el enfoque de los regímenes de bienestar para incorporar a los países subdesarrollados en una perspectiva comparativa. Dicho trabajo tiene el mérito de proponer categorías de análisis que ayuden a comprender la naturaleza de los regímenes en distintas regiones. A las tradicionales esferas que intervienen en el welfare mix —Estado, mercado y familia- suman otras, como la comunidad y los actores internacionales. Asimismo, la fuerte presencia de modalidades informales de provisión de bienestar, como el clientelismo, hace necesario incorporar una dimensión como la desclientelización que alude al grado en que las políticas sociales dejan de estar sujetas a relaciones clientelares.

Con ese marco analítico, Gough y Wood (2004) distinguen tres regímenes de bienestar a través de los continentes: regímenes estatales de bienestar (correspondientes a los países europeos), informales de seguridad (propio de los países asiáticos y de buena parte de los países latinoamericanos) y de inseguridad (característico de los países africanos). En Latinoamérica, los países del Cono Sur se encuentran en la frontera entre los regímenes informales de seguridad y los estatales de bienestar en la medida en que, si bien el Estado adquirió, desde mediados del siglo xx en adelante, un desarrollo significativo como agente de protección social, buena parte de la población debe confiar en un conjunto de 
arreglos informales para mantener su bienestar ${ }^{1}$. El resto de los países de la región considerados son catalogados como regímenes informales de seguridad $^{2}$ (Gough, 2004, p. 64).

Por otra parte, Haggard y Kaufman (2008) también realizan un análisis comparativo a gran escala en el que cotejan los sistemas de salud, educación y pensiones en América Latina, Europa del Este y Asia del Este, desde mediados del siglo xx, y los determinantes de las diferentes trayectorias seguidas en las tres regiones. Desde la segunda posguerra los países de Europa del Este contaban con un sistema de protección social y servicios sociales amplios para prácticamente toda la población, mientras que los del Este Asiático ofrecían sistemas de seguridad social mínimos que, sin embargo, otorgaban una alta prioridad a la educación.

La singularidad de los países de América Latina es que durante ese período adoptaron sistemas de seguridad social y de salud que favorecieron a los trabajadores formales, mientras excluyeron a los trabajadores informales. Además, los sistemas educativos tuvieron un desarrollo inferior que los de las otras regiones consideradas. Estos aspectos serán considerados en profundidad en las secciones siguientes.

\section{Los regímenes de políticas sociales en América Latina}

Teniendo en cuenta la discusión precedente, ¿es adecuado referirse a la noción de "Estado de bienestar" para el análisis de las sociedades latinoamericanas? Si no, ¿cuál es el concepto adecuado? Como se adelantó, la noción de Estado de bienestar surgió para caracterizar las experiencias específicas de los países desarrollados entre las décadas de los treinta y los sesenta en un contexto en que: "Su promesa no

\footnotetext{
1 Dichos países son: Argentina, Bolivia, Brasil, Chile y Colombia. Los datos en los que se basa este análisis corresponden al período 1996-2000.

2 Se trata de Guatemala, Honduras, Paraguay, Perú y Uruguay. Resulta llamativo que Uruguay figure en la categoría de "régimen de bienestar de seguridad informal" al no ser consistente con las otras clasificaciones de regímenes de bienestar disponibles para la región. Dicha discrepancia se debe al tipo de indicador de gasto público social utilizado para clasificar los casos que lleva a subestimar el tamaño del Estado social en Uruguay (Gough, 2004, p. 40).
} 
era meramente una política social que aliviara los males sociales y redistribuyera los riesgos básicos, sino un esfuerzo para reescribir el contrato social entre el gobierno y la ciudadanía" (Esping-Andersen, 2000, p. 50).

Mientras tanto, los países de América Latina presentan una diversidad significativa en lo que se refiere a la trayectoria histórica, tamaño y alcance de los programas de protección social. En la actualidad, se pueden distinguir dos grupos de países en función de la forma cómo se articulan el Estado, el mercado y las familias en la provisión de bienestar social. En el primero de ellos, compuesto por Argentina, Brasil, Chile, Costa Rica y Uruguay y México, el Estado tiene mayor presencia en la cobertura de los riesgos sociales, aun cuando sus regímenes de políticas sociales presentan un alto nivel de segmentación y de presencia del mercado. En el otro grupo, que integran Bolivia, Colombia, Ecuador, El Salvador, Guatemala, Honduras, Nicaragua, Panamá, Paraguay y Perú, el Estado tiene un rol marginal y las familias se ven recargadas ante la insuficiente incorporación en el mercado de trabajo y la ausencia de respuestas estatales para buena parte de la población (Cantu, 2015, pp. 67-68) ${ }^{3}$.

Por consiguiente, solo algunos de esos países tuvieron — o tienenun Estado de bienestar que se aproxima al que presentan los países desarrollados. Por ello, y a los efectos de contemplar las distintas realidades regionales, resulta pertinente utilizar los términos de "Estado social" o de "regímenes de políticas sociales". Este último es entendido como "el paquete de políticas provistas por el Estado para proteger a los ciudadanos de la pobreza y redistribuir ingresos y oportunidades" (Pribble, 2011, p. 192; traducción propia).

Teniendo en cuenta este concepto organizador, en lo que sigue se analiza la literatura que aborda los tres grandes períodos de la evolución de los regímenes de políticas sociales: i) la fase de surgimiento y consolidación

\footnotetext{
3 Como se verá más adelante, las otras clasificaciones existentes tienden a coincidir con la que aquí se referencia, aunque algunos distinguen tres en vez de dos grupos (véase también Midaglia \& Antía, 2017, pp. 63-64).
} 
de las políticas sociales que corresponde al modelo de desarrollo "hacia adentro", desplegado entre 1920 y 1980; ii) la etapa de reforma neoliberal de las políticas sociales entre las décadas de los ochenta y los noventa; y iii) la fase de "expansión segmentada" que se despliega desde el entorno de los años dos mil a la actualidad (Antía, 2013; Filgueira, 2015; Martínez Franzoni \& Sánchez-Ancochea, 2016a).

\section{La construcción de los regímenes de políticas sociales en el período 1920-1980}

Si bien en algunos países pioneros el origen de las principales políticas sociales se remonta a fines del siglo XIX (Filgueira, 2015; Larrañaga, 2010; Mesa-Lago, 1979; Papadópulos, 1992), el desarrollo de los regímenes de protección social, en la mayor parte de los países, se produjo durante el período 1920-1980. Las condiciones internacionales, en particular la contracción del comercio luego de la crisis de 1929, propiciaron el surgimiento de un nuevo estilo de desarrollo, pautado por la industrialización dirigida por el Estado. En este marco, el Estado amplió significativamente su acción en el campo económico y social y promovió la industrialización, fundamentalmente orientada al mercado interno (Draibe \& Riesco, 2006) ${ }^{4}$.

Se produjo así la creación o expansión de un conjunto de políticas sociales que se organizó en torno al mercado del trabajo. La seguridad social buscó proveer ingresos a los trabajadores y a sus familias ante los riesgos de vejez, viudez, invalidez y enfermedad. El alcance de la protección social fue parcial, ya que alcanzó únicamente a los trabajadores formales y a sus familiares, dejando desprotegidos a amplios segmentos de la población que tenían trabajos informales (Barrientos, 2004; Filgueira, 1998; Mesa-Lago, 1979).

Otro rasgo de los sistemas de seguridad social desarrollados en este período fue su alto nivel de segmentación entre categorías ocupacionales

\footnotetext{
4 Sobre las características de esta estrategia de desarrollo, también conocido como modelo de Industrialización por Sustitución de Importaciones (ISI), véase Hirschman (1968) y Bértola \& Ocampo (2010).
} 
que percibían distintos niveles de beneficios en reflejo de su poder relativo. En un trabajo precursor, Mesa-Lago (1979) mostraba que la incorporación de distintos grupos ocupacionales se produjo de forma secuencial y fragmentada, incluyendo primero a militares, empleados públicos y maestros, para extenderse más tardíamente a las demás categorías de trabajadores formales.

En la mayoría de los países el seguro de salud de los trabajadores formales fue financiado a partir de las contribuciones de dichos trabajadores, mientras que los sectores que no obtenían cobertura por esa vía, se atendían en los servicios — en general de baja calidad- que proveía el Estado (Haggard \& Kaufman, 2008, p. 32).

En el plano de la educación, el Estado asumió un papel importante en tanto financiador y proveedor. Se produjo una masificación de la educación primaria en los países menos avanzados y su universalización en los países pioneros, que también experimentaron una masificación de la educación secundaria (Filgueira, 2015, p. 62).

Si bien esas fueron las principales características generales de los regímenes de política social en la fase de construcción, que Barrientos (2004) sintetizó con el término "conservador-informal”, cabe destacar que los países tuvieron diferentes desarrollos. Mesa-Lago (1979, 1986), por ejemplo, clasifica a los países de acuerdo con el momento de surgimiento y el grado de desarrollo de los sistemas de seguridad social, distinguiendo entre los países pioneros, intermedios y

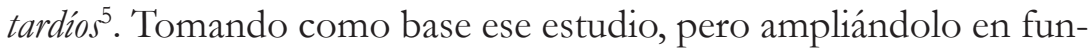
ción de otras dimensiones, Filgueira $(1998,2005)$ también identifica

\footnotetext{
5 El grupo pionero está compuesto por países que establecieron sistemas de seguridad social entre 1920 y 1930 y presentan la mayor cobertura y nivel desarrollo, pero con altos niveles de estratificación (Argentina, Chile, Cuba, Brasil y Uruguay). El grupo intermedio adoptó políticas de seguro social más tardíamente, en 1940, con una estructura más unificada, aunque de menor cobertura que el anterior (Colombia, Costa Rica, México, Paraguay, Perú y Venezuela). Finalmente, el grupo tardío creó sus sistemas de seguro social, de menor cobertura, entre las décadas de los cincuenta y los sesenta (el Caribe latinoamericano, con excepción de Cuba, y la mayoría de los países de Centroamérica, con excepción de Costa Rica y Panamá) (Mesa-Lago, 1986, pp. 133-136).
} 
tres tipos de regímenes de políticas sociales que denomina universalestratificado, dual y excluyente ${ }^{6}$.

El universal estratificado corresponde a Argentina, Chile y Uruguay. En este, la seguridad social y el servicio de salud protegían a la mayor parte de la población, al tiempo que la educación primaria y los primeros años de la secundaria se extendían a toda la población. La cobertura de la seguridad social tenía un carácter parcial al concentrarse en los trabajadores formales y, además, estaba segmentada según la inserción ocupacional (Filgueira, 2005; véase también Huber, 1996; Kaztman, 2002).

En el otro extremo se encuentran los regímenes excluyentes que comprendían a Bolivia, Ecuador y los países centroamericanos — con excepción de Costa Rica- La seguridad social abarcaba una baja proporción de la población y excluía a la amplia mayoría. La educación alcanzaba una cobertura relativa mayor, aunque tenía una calidad fuertemente segmentada (Filgueira, 1998, p. 15).

Los regimenes duales, que abarcaron a México y Brasil, se asemejaron al primer tipo en el medio urbano y al segundo tipo en el medio rural. Tuvieron un desarrollo casi universal de la educación primaria, un acceso estratificado a los servicios de salud y una escasa cobertura en la seguridad social con beneficios altamente estratificados (Filgueira, 2005, p. 25). Dichos beneficios eran percibidos como derechos corporativos antes que derechos ciudadanos (véase también Collier \& Collier, 1991).

Finalmente, Costa Rica no se ajusta a ninguno de los tipos anteriores, ya que "es el caso más próximo a un Estado social universal igualitario, o aún más, un Estado de bienestar socialdemócrata embrionario"

\footnotetext{
6 Barba (2007, pp. 202-203) plantea una categorización similar al distinguir entre regímenes universalistas (Chile, Argentina, Uruguay y Costa Rica), duales (Brasil, México, Colombia y Venezuela) y excluyentes (los países de América Central, con la excepción de Costa Rica, y Ecuador, Perú, Bolivia y Paraguay). Los regímenes se sitúan en distintos "escalones" de bienestar, lo que se materializa en indicadores tales como los niveles de empleo formal, la cuantía del gasto social o la cobertura de los servicios sociales.
} 
(Filgueira, 2007, p. 10; traducción propia). En ese país, la seguridad social alcanzó una amplia cobertura y una baja segmentación, al tiempo que se generó una amplia expansión de los servicios de educación y salud a casi toda la población (Martínez Franzoni \& Sánchez-Ancochea, 2013a).

En suma, la mayoría de los países de la región presentó regímenes de política social "truncados" (Lindert, Skoufias, \& Shapiro, 2006) ya que la cobertura era parcial y, además, altamente segmentada. Dicha configuración tuvo consecuencias duraderas, de largo plazo, sobre los regímenes de políticas sociales cuyos rasgos principales, aunque sujetos a reformas, persistieron en etapas posteriores (Haggard \& Kaufman, 2008; Pribble, 2011).

\section{La economía política durante la fase de construcción de los regímenes de política social}

¿Qué elementos explican la construcción de sistemas de políticas sociales truncados y estratificados? ¿Por qué algunos países consiguieron avanzar más que otros en materia de protección social? La mayor parte de los estudios se ha centrado en la caracterización de los regímenes de políticas sociales antes que en sus causas. No obstante, es posible identificar tres tipos de trabajos que han incursionado en el estudio de los orígenes de las políticas sociales en la región.

En primer lugar, existe una multiplicidad de estudios de caso que ofrecen explicaciones sobre la trayectoria de la política social en algunos países específicos ${ }^{7}$, pero solo algunos mantienen un diálogo con la literatura de los determinantes del bienestar a nivel comparado.

En segundo lugar, los estudios comparativos se inician con las investigaciones de Mesa-Lago $(1979,1986)$ antes mencionadas, cuyo foco estaba en el poder relativo de las categorías ocupacionales incorporadas a los regímenes de seguridad social.

\footnotetext{
7 A modo ilustrativo, véase: Isuani (1985) sobre Argentina; Malloy (1979) sobre Brasil; Papadópulos (1992) sobre Uruguay; Borzutzky (2002) y Larrañaga (2010) sobre Chile; Martínez Franzoni \& Sánchez-Ancochea (2013a) sobre Costa Rica.
} 
En tercer lugar, más recientemente, han surgido estudios comparativos que ponen el foco en otros factores explicativos relativos a las características del modelo económico imperante, la presencia de instituciones democráticas y las modalidades de incorporación de los trabajadores a la arena política. Esta literatura establece un diálogo más directo con los estudios comparados sobre los determinantes de las políticas de bienestar social.

En este marco, Filgueira $(2005,2007)$ distingue diferentes dinámicas políticas que orientaron la creación de los tres regímenes de política social. El universalismo estratificado fue producto de la competencia entre élites políticas que buscaban el apoyo popular en el marco de una política de masas inclusiva en países que fueron, además, pioneros en el desarrollo de las políticas de la ISI. El régimen dual respondió al proceso de construcción del Estado por parte de las élites y la cooptación y represión del sector popular en el contexto de un débil e inestable proceso de competencia democrática. El régimen excluyente resultó de la existencia de élites "depredadoras". Finalmente, en Costa Rica, la existencia de elecciones competitivas y una participación electoral amplia, junto a un Estado relativamente autónomo y profesional, ambientaron los mayores avances en la región en materia de protección social ${ }^{8}$.

Por su parte, Segura-Ubiergo (2007) identifica un conjunto de condiciones favorables para el desarrollo de los regímenes de política social más generosos en la región, presentes en Argentina, Brasil, Chile, Costa Rica y Uruguay. Esos factores son: i) el nivel de desarrollo económico y de industrialización que contribuyen a aumentar la capacidad fiscal de los Estados; ii) las políticas económicas proteccionistas que facilitan la expansión de una masa de trabajadores capaz de presionar por la creación de programas sociales; iii) y una mayor tradición democrática o un mayor poder de la izquierda política y de los movimientos sindicales en comparación con el resto de los países de la región (SeguraUbiergo, 2007, pp. 69-70).

8 Véase Martínez Franzoni \& Sánchez-Ancochea (2013a). 
$\mathrm{El}$ autor distingue dos trayectorias. Un primer camino corresponde a los países que tuvieron condiciones económicas favorables y una economía cerrada, en los que la presencia de regímenes democráticos (Brasil) o de partidos de izquierda y movimientos obreros (Argentina), o de ambas condiciones (Chile y Uruguay), favorecieron la consolidación de sistemas de protección social generosos. El segundo camino, presente en Costa Rica, combinó un bajo nivel de desarrollo económico y una cierta apertura económica. En ese contexto, tanto la democracia como la existencia de movimientos de izquierda-obrera se tornaron necesarios para la consolidación de un sistema de protección social generoso (Segura-Ubiergo, 2007, pp. 71-72).

Desde otro ángulo, Haggard y Kaufman (2008) argumentan que el origen y desarrollo de los regímenes de políticas sociales en los nueve países que abordan ${ }^{9}$ se debió a tres factores: el realineamiento crítico, el modelo de desarrollo económico y el régimen político. Siguiendo el trabajo seminal de Collier y Collier (1991), los autores argumentan que durante la primera mitad del siglo xx las élites políticas reformistas incorporaron a los trabajadores formales urbanos, procurando su apoyo o desmovilización, según el caso, a partir de la creación de los sistemas de seguridad social y de salud (Haggard \& Kaufman, 2008, pp. 45-51). El modelo de la ISI permitió la expansión de ese tipo políticas, pero al mismo tiempo redujo los incentivos para que gobiernos, empresas y trabajadores invirtieran en educación, estableciendo uno de los rasgos distintivos de los países latinoamericanos en comparación con otras regiones (Haggard \& Kaufman, 2008, pp. 64-65). Finalmente, los países que contaron con regímenes democráticos más estables tuvieron políticas sociales amplias, en tanto los regímenes autoritarios tendieron a recortar o racionalizar los beneficios sociales antes que a expandirlos (con la excepción de México y Brasil) (Haggard \& Kaufman, 2008, pp. 79-84).

Además, el último libro de Huber \& Stephens (2012) también analiza los determinantes de la política social en la región a partir de la combinación de un estudio cuantitativo, que incluye a la totalidad de los países

\footnotetext{
9 Argentina, Brasil, Chile, Colombia, Costa Rica, México, Perú, Venezuela y Uruguay.
} 
de América Latina, y un estudio histórico comparado de los cinco países de la región que cuentan con políticas sociales más avanzadas ${ }^{10}$. Esa investigación se concentra en dos de los factores planteados antes, ya que identifica una fuerte relación entre la democracia y la fortaleza de los partidos de izquierda con la expansión del gasto público social. En tal sentido, la democracia genera condiciones propicias para la expansión del gasto social, además de ser una precondición para la formación de partidos de izquierda y su posible acceso al poder, contribuyendo a la expansión de las políticas sociales (Huber \& Stephens, 2012).

Finalmente, Pribble (2011) identifica, mediante un estudio histórico comparado que abarca un mayor número de países, cuatro trayectorias en la construcción de los regímenes de políticas sociales. Las condiciones explicativas clave son las secuencias y niveles de industrialización y de incorporación política del sector popular.

Según la autora, una primera trayectoria, que dio lugar a las políticas sociales más avanzadas en Argentina, Chile, Costa Rica y Uruguay, es la de los países que experimentaron una industrialización significativa y el sector popular fue integrado a través de un proceso de movilización. La segunda trayectoria fue la de las naciones que tuvieron un proceso de industrialización significativo, pero incorporaron el sector popular a través de formas de control, dando lugar a un régimen de políticas sociales cuyo énfasis estuvo en las políticas de seguridad social, mientras que las políticas educativas y sanitarias tuvieron un desarrollo inferior. Se trata de Brasil, México y Panamá. Una tercera trayectoria responde a los casos en los que la industrialización fue intermedia y se produjeron períodos breves de incorporación política seguidos de represión, que se tradujo en cierto desarrollo de la política educativa y de salud, pero escaso desarrollo de la política previsional (Colombia, Paraguay, Ecuador y Perú). Finalmente, la cuarta trayectoria fue la de los países que tuvieron un bajo nivel de industrialización y en los que no hubo inclusión política de los grupos marginados hasta fines del siglo xx. Esos países —El

10 Argentina, Brasil, Chile, Costa Rica y Uruguay. 
Salvador, Guatemala, Nicaragua y República Dominicana- tuvieron un escaso desarrollo de sus políticas sociales.

En suma, aun con diferentes abordajes teóricos y metodológicos, los estudios indican la relevancia que los niveles de industrialización, la presencia de instituciones democráticas y los distintos formatos de incorporación de los trabajadores a la esfera política tienen para comprender buena parte de la variación entre los regímenes de políticas sociales durante la etapa de desarrollo hacia adentro. Si bien esta literatura realiza una contribución relevante, cabe destacar tres limitaciones: i) en general, los estudios comparativos tienden a concentrarse en el grupo de países que tienen políticas sociales más avanzados (con excepción del estudio de Pribble, 2011); ii) hay una escasa problematización del rol de los regímenes autoritarios con relación a las políticas sociales (con la salvedad de Garay, 2016, pp. 80-82; Mares \& Carnes, 2009, pp. 96-101); y iii) se presta poca atención al rol de las ideas internacionales, los técnicos y los procesos de difusión para explicar la adopción de principios y formas de organización de las políticas sociales (con excepción de Malloy, 1979 y Martínez Franzoni \& Sánchez-Ancochea, 2013a). Estos últimos aspectos adquirieron, como se verá, relevancia en la literatura que considera la adopción de las reformas que tuvieron lugar a partir de la década de los ochenta.

\section{Los regímenes de políticas sociales durante el giro neoliberal de los ochenta y los noventa}

Con el agotamiento del modelo ISI y el avance de las ideas neoliberales, los países de la región comenzaron a introducir amplias reformas en sus regímenes de políticas sociales. La crisis de la deuda externa, desatada en 1982, generó un punto de inflexión en la estrategia de desarrollo que marcó el tránsito hacia un modelo pautado por la reducción del Estado, la apertura comercial y la liberalización de la economía (Stallings, 1992; Evans \& Sewell, 2013), sintetizado en el "Consenso de Washington" (Williamson, 1990). A escala regional, la influencia de los gobiernos de los países acreedores de la deuda y los organismos financieros internacionales aumentaron significativamente, tanto en el campo económico como en el de las políticas sociales (Deacon, 2007; Stallings, 1992). 
En este último ámbito también se produjo un cambio ideológico. La agenda de reformas estableció la jerarquización del mercado como prestador de servicios sociales, la descentralización como estrategia de gestión y la focalización en los sectores más pobres (Franco, 1996; Filgueira, 1998).

Estas tendencias comenzaron a plasmarse en la década de los ochenta que coincidió, en la mayoría de los países, con la democratización de los regímenes políticos. No obstante, ese período estuvo pautado por la severa contracción de las economías, la crisis fiscal y los desequilibrios inflacionarios (CEPAL, 1996), con lo cual los gobiernos tendieron a desatender los problemas sociales (Filgueira, 2005; Hardy, 2011). El gasto público social se redujo (Cominetti \& Ruiz, 1998, p. 27) y se crearon Fondos de Emergencia Social promovidos por los organismos multilaterales de crédito como una fórmula para compensar los impactos sociales del ajuste estructural (Fleury, 1999) y contribuir a la generación de apoyos a esas reformas (Ezcurra, 1996).

En esa década no se adoptaron otras reformas sustantivas en la mayor parte de la región (Filgueira, 2005, p. 39), con excepción de Chile, que durante la dictadura impuso un conjunto de reformas neoliberales en seguridad social, educación y salud (Borzutzky, 2002; Castiglioni, 2005).

Durante la década de los noventa, el gasto público social se expandió en los países que ya destinaban mayor cantidad de recursos a ese rubro, pero eso no ocurrió en los países de menor gasto relativo que no recuperaron el nivel de desembolsos de inicios de la década anterior (Cominetti \& Ruiz, 1998, pp. 29-30).

En paralelo, se adoptaron reformas de orientación neoliberal en la seguridad social, la educación, la salud y el trabajo. En el campo previsional, se introdujeron nuevos pilares de capitalización individual y se tendió a endurecer los requisitos para la jubilación (Mesa-Lago, 2008). En el plano laboral, se promovió la desregulación de los mercados de trabajo (Cook, 2007), pero estos mostraron en general malos desempeños al 
presentar altas tasas de desempleo e informalidad ${ }^{11}$. Ello, junto a la profundización de las bases contributivas y actuariales de los sistemas jubilatorios, hizo más difícil que la población reuniera las condiciones necesarias para retirarse (Arza, 2008). Los resultados decepcionantes en este plano ambientaron, en los dos mil, nuevas reformas de varios aspectos de los sistemas de pensiones (Antía \& Lanzara, 2011).

En lo que refiere al campo de la salud, las reformas tendieron a fortalecer el mercado como proveedor de servicios — con el caso paradigmático de Chile — pero en otros países — como Costa Rica y Brasil-incluyeron consideraciones de equidad (Mesa-Lago, 2007, p. 162; Kaufman \& Nelson, 2004). De hecho, las reformas no siguieron un patrón único, al punto que Mesa-Lago (2008, p. 58) identifica un total de diez modelos de reforma diferentes.

En el ámbito de la educación tampoco hubo un único camino de reformas. De acuerdo con Gajardo (1999) y Kaufman y Nelson (2004), el cambio estructural más generalizado fue la descentralización, aunque también hubo reformas orientadas a ampliar la cobertura estatal y a fortalecer la equidad de los sistemas educativos (Bentancur, 2008; Huber \& Stephens, 2012, p. 177).

Aparte de las reformas sectoriales, la focalización del gasto pasó a ser uno de los principios orientadores de las políticas sociales. Junto a los Fondos de Emergencia Social, se crearon otras políticas focalizadas en los más pobres con el propósito de "combatir la pobreza". No obstante, esas políticas tuvieron un alcance acotado, por lo que la ausencia de una red de protección básica dejó descubierta a gran parte de la población que tenía trabajos informales (Huber \& Stephens, 2012, p. 176).

Ese aspecto, junto a la orientación liberal de las reformas de las políticas sociales, llevó a que Barrientos (2004) calificara a los regímenes de políticas sociales en términos de liberales-informales. En esa misma

\footnotetext{
11 Por ejemplo, entre los empleados urbanos, en 1999 el $46 \%$ era informal (OIT, 2000, cuadro 6-A).
} 
línea, Martínez Franzoni (2008) concluye que en el período 19982003 todos los países tenían regímenes de bienestar informales, ya que una alta proporción de la población no encontraba respuestas a los riesgos sociales en el mercado de trabajo o en los servicios públicos y, como consecuencia, el trabajo femenino no remunerado desempeñaba un papel fundamental.

Aunque esa fue la orientación predominante, las reformas neoliberales tuvieron alcances y ritmos diferentes tanto a nivel sectorial como entre países (Filgueira, 2005; Kaztman, 2002). Como reflejo de esto, y de las configuraciones de larga data de las políticas sociales, Martínez Franzoni (2008) identifica tres patrones regionales según los niveles de mercantilización, desmercantilización y familiarización de los arreglos de bienestar. Un grupo de países tenía, a inicios de siglo, un régimen estatal-proteccionista (Costa Rica, Brasil, México y Uruguay), otro estatal-productivista (Argentina y Chile) y el tercero familiarista (Colombia, Ecuador, El Salvador, Guatemala, entre otros).

En síntesis, los estudios reseñados muestran que los regímenes de políticas sociales continuaron teniendo, en este período, un carácter truncado que ofrecía una cobertura restringida a los trabajadores formales, así como una persistente segmentación en la calidad de la protección social. Dicha segmentación se vio reforzada por la incorporación y expansión del mercado como principio y agente de prestación en el campo de seguridad social, la educación y la salud (véase Barrientos, 2009; Cantu, 2015).

En contraste con estas tendencias, desde fines de los ochenta y sobre todo en los noventa, varias naciones pasaron a incluir un conjunto de derechos sociales en sus nuevas constituciones (Brinks \& Forbath, 2013, pp. 223-224; Krennerich \& Góngora Mera, 2006, p. 3; Noguera Fernández, 2010, pp. 46-47) ${ }^{12}$. El cumplimiento de los nuevos derechos pasó a depender, en varios países, del activismo de las cortes

12 Esto sucedió especialmente en Argentina, Brasil, Bolivia, Colombia, Ecuador y Venezuela. 
en alianza con movimientos sociales que impulsaban la defensa de aquellos (Brinks \& Forbath, 2013).

El grado en que el ámbito judicial se convirtió en una arena que condujo al reconocimiento y a la implementación efectiva de los derechos sociales varió fuertemente en las distintas experiencias nacionales. En algunos casos, como Colombia, Costa Rica o Brasil, las cortes superiores de Justicia pasaron a jugar un papel relevante como garantes de la implementación de un conjunto de derechos sociales, mientras que en otros, como por ejemplo, en Chile o en Uruguay, el activismo de dicha institución fue menor (Brinks \& Forbath, 2013, p. 239) ${ }^{13}$.

\section{La economía política de las reformas neoliberales}

Los estudios sobre los determinantes de las reformas de las políticas sociales en esta etapa destacan la importancia de la influencia externa, que se manifestó a través de la crisis de la deuda, el papel de las agencias multilaterales de crédito o la emulación de modelos de políticas sociales adoptados por otros países (Weyland, 2006; Deacon, 2007; Haggard \& Kaufman, 2008; Huber \& Stephens, 2012). Sin embargo, no todos coinciden en las modalidades en que se canalizó dicha influencia. Mientras Huber \& Stephens 2012, p. 156) plantean que "la influencia se produjo a través de la condicionalidad directa, e, igualmente importante, a través de redes informales", Weyland (2006) señala que, más que a presiones verticales, la adopción de las reformas de pensiones y de salud respondió a un proceso de contagio horizontal entre países vecinos (véase Meseguer, 2009).

La literatura discute también el impacto de la globalización sobre los regímenes de política social, aunque las evaluaciones cuantitativas llegan a resultados diferentes. Segura-Ubiergo (2007) y Rudra (2008) encuentran que la mayor integración de las economías al comercio internacional tuvo efectos negativos sobre el gasto social agregado,

\footnotetext{
13 Para otros abordajes sobre la temática, véase Gauri \& Brinks (2010); Rodríguez Garavito (2011).
} 
a diferencia de lo que ocurrió en los países desarrollados. En cambio, Avelino, Brown, \& Hunter (2005) concluyen que la movilidad de capitales y la integración de las economías no generó necesariamente restricciones en el gasto social y que, en combinación con la democracia, pudo incluso estimular el gasto social.

Los distintos estudios coinciden en señalar que la adopción de la agenda neoliberal varió entre los países en función, principalmente, de factores domésticos. Según Huber \& Stephens (2012, pp. 156-157), los elementos gravitantes fueron el balance de poder entre quienes apoyaban y quienes se oponían a las reformas y los legados de las políticas sociales del período ISI, en particular en los países que tenían regímenes de pensiones más maduros y costosos, que hicieron que las presiones para impulsar las reformas fueran superiores que en el resto.

En este marco, otro asunto relevante es si la ola de democracias que inició en los ochenta se asoció con una expansión de las políticas sociales. Con relación a este aspecto, las expectativas son ambiguas ya que, por un lado, la democracia generaría incentivos para extender la protección social hacia grupos no cubiertos, pero al mismo tiempo abriría oportunidades para que los beneficiarios de las políticas establecidas protegieran sus intereses, en particular en los países que tenían regímenes de bienestar de mayor cobertura (Haggard \& Kaufman, 2008, p. 265-266; Segura-Ubiergo, 2007, p. 256). En tal sentido, cobran importancia los legados de las políticas sociales establecidas durante el período ISI. Los esfuerzos por recortar los beneficios existentes generaron, en general, oposición de los sectores beneficiarios ${ }^{14}$.

La revisión mostró también que son pocos los estudios que aborden los determinantes de la reforma de los regímenes de políticas sociales en su conjunto, mientras que predominan los estudios que

\footnotetext{
14 Los resultados empíricos del impacto de la democracia en el nivel de gasto social indican que esta no se asocia con un aumento del gasto en seguridad social, pero sí con un mayor gasto en educación y salud, que son los que tienen un impacto más progresivo (SeguraUbiergo, 2007, p. 256). Entre tanto, Huber y Stephens (2012), analizando un período más amplio (1970-2005), encuentran que la democracia se asocia con un aumento en las tres categorías del gasto social.
} 
se concentran en algún sector de la política, asunto o país ${ }^{15}$. Específicamente, en el plano sectorial, el asunto más estudiado fue la ola de privatizaciones en los sistemas de pensiones (Brooks, 2008; Kay, 1999; Madrid, 2003), mientras son menos los trabajos que abordan la dinámica política de las reformas de los servicios sociales (Kaufman \& Nelson, 2004; Murillo, 1999). Además, los estudios no suelen explicar las divergencias entre áreas de políticas sociales, tanto dentro de un país, como entre países (Mares \& Carnes, 2009, p. 95).

\section{La "expansión segmentada" de las políticas sociales en los dos mil'16}

A diferencia de la fase de recortes, en los dos mil se comenzó a plantear, tanto desde tiendas académicas ${ }^{17}$ como desde los principales organismos internacionales ${ }^{18}$, una nueva agenda de reformas de las políticas sociales. En este giro en las ideas algunos destacaron la necesidad de que el Estado asumiera una mayor responsabilidad en la protección social, impulsara políticas de "inversión social" o reformas que se orientaran a partir de principios universales.

El nuevo contexto, pautado por el crecimiento económico y un balance de poder político diferente en el marco de democracias que se estabilizaron en buena parte de la región, resultó propicio para la expansión de las políticas sociales. Asimismo, la asunción de numerosos gobiernos de izquierda y de centro-izquierda también contribuyó a hacer posible esa orientación de reformas (Huber \& Stephens, 2012; Pribble, 2013), aunque cabe señalar que gobiernos de distinto

\footnotetext{
15 Sobre el análisis de países específicos, véase: Borzutzky (2002); Castiglioni (2005); Dion (2010).

16 Sigo aquí el término utilizado por Martínez Franzoni \& Sánchez-Ancochea (2016) para caracterizar la orientación de los cambios de las políticas sociales en este período.

17 Véase: Molina (2006); Huber \& Stephens (2012); Pribble (2013); Martínez Franzoni \& Sánchez-Ancochea (2016b).

18 Por ejemplo: CePal (2010); OIT (2011); Orszag \& Stiglitz (2001). Para una revisión, véase: Jenson (2010).
} 
signo ideológico se abocaron a la ampliación de la protección social (Fairfield \& Garay, 2017; Garay, 2016).

Las innovaciones se plantearon principalmente en cuatro campos: i) la expansión de la asistencia social dirigida a las familias vulnerables con hijos; ii) las reformas de los sistemas de seguridad social; iii) las reformas de los sistemas de salud; y, finalmente, iv) la expansión de la educación (Filgueira, 2015; Martínez Franzoni \& Sánchez-Ancochea, 2016a).

En efecto, el cambio más generalizado fue la creación de las transferencias monetarias dirigidas a las familias pobres o vulnerables con hijos a cargo, en general condicionadas a que asistieran a la escuela y se realizaran chequeos periódicos de salud (Cecchini \& Madariaga, 2011; Fiszbein et al., 2009). Luego de las experiencias pioneras en Brasil y México de fines de los noventa, esos programas, conocidos como transferencias monetarias condicionadas (TMC), se extendieron a buena parte de la región en los dos mil ${ }^{19}$. Las TMC alcanzaron niveles de cobertura masiva aunque implicaron un bajo presupuesto, cercano a medio punto del PBI (sobre la base de CEPAL, 2017). Presentaron, además, una diversidad de modelos en lo atinente a los montos transferidos, el alcance, las formas de financiamiento y las modalidades de implementación de las condicionalidades (Garay, 2016, p. 15; Antía, Rossel, \& Manzi, 2017).

En el plano de las pensiones, las reformas también se generalizaron. Rofman, Apella y Vezza (2015) muestran que, entre 2000 y 2013, un total de 18 países realizaron reformas inclusivas que buscaron mejorar la protección social de la población adulto mayor. La mayoría creó o expandió la cobertura de las pensiones no contributivas financiadas por tributos (Carnes \& Mares, 2014), aunque siguiendo distintos modelos (Arza \& Chahbenderian, 2014; Rofman et al., 2015). Algunos gobiernos, como los de Chile, Uruguay, Costa Rica y Argentina optaron, además, por volver a reformar sus sistemas contributivos al flexibilizar algunas de las condiciones para acceder a las prestaciones. En Argentina y Bolivia,

19 En 2014, 21 países de América Latina y el Caribe contaban con un programa de ese tipo (CEPAL, 2016, cuadro IV.7). 
se produjo la estatización de los sistemas de jubilaciones lo cual implicó, en el primero, la clausura del pilar de capitalización individual creado en los noventa (Arza, 2012; Calvo, Bertranou, \& Bertranou, 2010).

En lo que concierne a la salud, se promovió una expansión del acceso y del aseguramiento de la población, aunque se hizo a partir de diferentes modelos. Por un lado, la creación del Seguro Popular en México expandió la cobertura hacia la población pobre mediante la creación de un paquete de servicios básicos (Barba \& Valencia, 2015, pp. 61-62; Garay, 2016, pp. 245-250). En cambio, en otros países como Brasil, Chile y Uruguay, no solo se amplió el acceso a los servicios de salud, sino que también se buscó mejorar la suficiencia y la equidad en dichas prestaciones, aunque persistió la segmentación de la calidad del servicio entre distintos grupos (Martínez Franzoni \& Sánchez-Ancochea, 2016).

Asimismo, en la agenda de los gobiernos de algunos países ingresó el tema relativo a los cuidados de la población dependiente. No obstante, los avances en este plano han sido dispares (Blofield \& Martinez Franzoni, 2015; Filgueira, 2013, pp. 35-36). En general, los principales cambios se vincularon al sistema educativo, a partir de la expansión de la educación preescolar y, en algunos casos, de la creación de servicios de educación y cuidado dirigidos a niños aún más pequeños (Itzcovich, 2013).

Desde el punto de vista financiero, la expansión del papel del Estado estuvo acompañada por un aumento sustantivo de los recursos destinados al gasto público social que, en promedio, se ubicaba en 12,6\% del PBI a comienzos de los noventa y pasó a 19,5 \% del PBI en 20132014 (CEPAL, 2016, p. 61).

Miradas en conjunto, las reformas adoptadas en los dos mil consiguieron extender la cobertura de las políticas sociales hacia un amplio sector de la población que antes no accedía a la misma o lo hacía en condiciones de calidad insuficiente, ampliando el papel del Estado. No obstante, ese proceso de incorporación tuvo lugar de forma segmentada, esto es, estableciendo diferentes parámetros de calidad en 
las prestaciones que se dirigen a los sectores tradicionalmente protegidos (en particular, los trabajadores formales) y los que ahora se incluyeron (grosso modo, los trabajadores informales y desempleados) (Antía, 2013; Barrientos, 2009). Cabe distinguir, no obstante, diferentes modelos de expansión. Por ejemplo, entre los países que cuentan con un mayor nivel de ingresos en la región, Garay (2016) identifica un modelo de expansión de tipo restrictivo en Chile y México y otro modelo de rasgos inclusivos en Argentina, Brasil y Uruguay ${ }^{20}$.

Otro aspecto para destacar es que a pesar de la expansión del rol del Estado que se produjo en el campo de la protección social durante los años dos mil (Carnes \& Mares, 2015), el mercado siguió teniendo una presencia relevante como principio organizador de los regímenes de política social en campos tales como la previsión social, la salud o la educación. En efecto, si bien el papel del mercado no aumentó en este último período, tampoco se redujo sustantivamente (Barrientos, 2009; Cantu, 2015).

Por consiguiente, Cantu (2015) muestra que luego de un período de aproximadamente diez años de expansión de la protección social, los países aún se agrupan en categorías similares a la década previa: dos grupos de países cuentan con regímenes de política social de carácter excluyente en los que el Estado tiene un rol marginal; en tanto los otros dos grupos de naciones disponen de regímenes de políticas sociales con mayor presencia estatal, aunque las políticas sociales conservan un carácter segmentado y el mercado mantiene un papel relevante en tanto principio organizador de la protección social ${ }^{21}$.

\footnotetext{
20. La diferencia entre uno y otro radica en la cobertura, la generosidad de los beneficios y la participación de organizaciones sociales en la implementación de las políticas (Garay, 2016).

21 Entre los primeros, de carácter excluyente, se identifican dos subgrupos. Uno, caracterizado como excluyente familiarista en el que las carencias del mercado de trabajo y de las respuestas brindadas por el Estado a los riesgos sociales que experimenta la población recargan fuertemente a las familias (Bolivia, Colombia, Ecuador, Guatemala, Panamá, Paraguay y Perú). El otro, denominado excluyente migratorio, en el que la migración es una estrategia extendida entre la población pobre (El Salvador, Honduras, Nicaragua). Entre los segundos, en los que el Estado asume un mayor protagonismo, se identifican dos subgrupos: el primero es el liberal moderado, donde la protección social tiene un carácter estatal, estratificado y liberal (comprende a Argentina, Brasil, Costa Rica y Uruguay). El segundo es el liberal radical, que
} 


\section{La economía política de la expansión segmentada}

La expansión de la protección social es un fenómeno político relevante que algunos autores incluso han identificado como parte y señal de un proceso de "segunda incorporación" del sector popular (Garay, 2007; Rossi, 2015; Silva, 2017), con rasgos propios que lo diferencian del proceso de "incorporación inicial" que tuvo lugar durante la primera mitad del siglo xx (véase Collier \& Collier, 1991).

¿Cuáles fueron las causas de la expansión segmentada de la protección social que se produjo en los dos mil? ¿Por qué la ampliación de la cobertura hacia la población más vulnerable se produjo en este momento histórico, luego de un largo período de negligencia? ¿Qué factores explican las diferencias entre países?

Las investigaciones que abordan estas temáticas están aún en desarrollo y en general consideran un número limitado de países. Un primer conjunto de estudios se concentra en explicar el proceso de expansión de las políticas sociales hacia la población más vulnerable o outsiders, mientras que un segundo grupo analiza los determinantes del carácter segmentado de dicha expansión.

Entre los primeros, los principales argumentos explicativos refieren a: i) los procesos de difusión de políticas (Brooks, 2015; Sugiyama, 2011); ii) la desindustrialización y sus impactos sobre las preferencias de la población y las coaliciones políticas (Carnes \& Mares, 2014, 2015); iii) la estabilidad democrática y la presencia de gobiernos de izquierda (Huber \& Stephens, 2012); y iv) la configuración de la competencia electoral y la movilización de organizaciones sociales (Garay, 2016).

Así, un primer argumento pone el foco en los procesos de difusión de las políticas sociales entre distintos países al analizar, en particular, la generalización de las TMC en los países de la región. Brooks (2015)

se identifica como estatal, estratificado y liberal avanzado en la medida en que cuenta con una fuerte presencia del mercado en los servicios de salud y educación (Chile y México) (Cantu, 2015, pp. 67-68). 
muestra que ese nuevo modelo de política social se difundió regionalmente en un período relativamente corto de tiempo y concluye que la probabilidad de que un país adopte un programa de este tipo aumenta con la prevalencia de las TMC en la misma región (véase también Sugiyama, 2011). No obstante, la difusión no parece haber sido el motor en la expansión de otras políticas sociales como las de salud y las de pensiones que respondieron fundamentalmente a procesos domésticos (Garay, 2016).

En otro registro, Carnes \& Mares (2014) procuran identificar los microfundamentos, a nivel de las preferencias de los individuos, que están en la base de la expansión de las políticas no contributivas - en el campo de la salud, pensiones o TMC - que tuvo lugar en la región en los dos mil. Según argumentan, la desindustrialización de las economías latinoamericanas que se produjo desde el último tercio del siglo xx habría generado las precondiciones para la expansión de las políticas sociales no contributivas, en particular de las pensiones ${ }^{22}$. En ese sentido, la reducción simultánea del empleo en la industria y en el sector agropecuario, junto con el aumento de la informalidad laboral, dio lugar a un incremento de los empleos vulnerables, todo lo cual ambientó cambios en las preferencias de los individuos relativas a las políticas sociales. Eso habría conducido al debilitamiento de las coaliciones de apoyo que favorecían la protección social de los trabajadores formales y habría generado oportunidades para la creación de coaliciones, compuestas por los trabajadores formales vulnerables y los sectores informales tradicionalmente excluidos, que sustentaran la expansión de las políticas sociales no contributivas.

Por su parte, un tercer argumento es el planteado por Huber y Stephens (2012) quienes sostienen que los cambios en la orientación de las políticas sociales de inicios del siglo XXI deben atribuirse al "giro a la izquierda" que se vivió en varios países de la región, propiciado a su vez por la estabilidad de las instituciones democráticas. En una línea similar, varios estudios indican que el crecimiento económico

22 Sobre las preferencias de los ciudadanos con relación al sistema de salud no contributivo, véase Carnes \& Mares (2015). 
ligado al boom de las exportaciones de los commodities, en los dos mil, permitió que las izquierdas implementaran su agenda redistributiva, a diferencia de lo que había sucedido en la década previa (Campello, 2015; Levitsky \& Roberts, 2011).

Luego, el cuarto argumento es planteado por Garay (2016), quien especifica con mayor precisión las condiciones que habrían conducido a la expansión de las políticas sociales hacia los outsiders, colocando el foco en cuatro de los países de mayor desarrollo de la región: Argentina, Brasil, Chile y México. La autora muestra que, desde fines de la década de los ochenta, estas naciones incorporaron a los outsiders de forma masiva y no discrecional en distintas políticas sociales. El argumento explicativo indica que: "[...] los gobiernos expandieron las políticas sociales cuando se enfrentaron con altos niveles de competencia electoral por el voto de los outsiders y/o con una fuerte movilización social de parte de coaliciones de movimientos sociales y sindicatos que presionaron por la expansión de las políticas sociales" (Garay, 2016, p. 18; traducción propia). Sin embargo, cuando las democracias carecieron de esas condiciones, los gobiernos no adoptaron una expansión de gran escala y no discrecional de la protección social ${ }^{23}$.

El predominio de una u otra dinámica política — competencia electoral o movilización social— condujo a distintos modelos de política social. Cuando la expansión respondió a la competencia electoral, dio lugar a un modelo de política social restrictivo, como ocurrió en Chile y México. Por otra parte, cuando el motor estuvo en la movilización

\footnotetext{
23 La literatura ha comenzado a ocuparse del análisis de los determinantes de otros aspectos salientes del proceso de expansión, como es la reducción del clientelismo y la discrecionalidad en buena parte de las políticas en este período. En tal sentido, Garay (2016, p. 336) argumenta que la intensa competencia por el voto de los outsiders y la movilización social en demanda de protección social generaron condiciones propicias para la creación de beneficios sociales no clientelares. En paralelo, De la O (2015) destaca que los gobiernos de la región tendieron a adoptar TMC no discrecionales cuando enfrentaron un Congreso en el que la oposición tenía la mayoría.
} 
social, las reformas tendieron a un modelo de política social inclusivo, como sucedió en Argentina y Brasil (Garay, 2016) ${ }^{24}$.

En todo caso, sin desconocer la influencia de los gobiernos de izquierda como promotores del cambio de las políticas sociales, el estudio de Garay permite especificar las condiciones en las que los gobiernos de izquierda impulsan una expansión de las políticas sociales, al tiempo que explicar la dinámica política que condujo a la expansión de la protección social por parte de gobiernos de centro o de derecha. Lo último ocurrió, por ejemplo, durante las administraciones de Vicente Fox (2000-2006) en México o de Sebastián Piñeira (2010-2014) en Chile. En esos casos, la competencia electoral motivó la expansión de las políticas sociales hacia los outsiders, aunque las iniciativas fueron más modestas cuando predominaron los partidos de derecha (véase también: Fairfield \& Garay, 2017).

En síntesis, esta revisión de la literatura reciente permitió constatar que la mayoría de los estudios explican el proceso de expansión de la protección social hacia la población antes no cubierta, pero ponen menor énfasis en la explicación de los procesos políticos que condujeron al carácter segmentado de dicha expansión. Hay, sin embargo, dos excepciones que cabe destacar.

La primera de estas excepciones es el estudio de Ewig y Kay (2011), quienes argumentan que la dinámica política de la fase de expansión está fuertemente condicionada por los legados del período de recorte de las políticas sociales. Dichos legados incluyen la presencia de nuevos actores, principalmente los poderosos proveedores privados, como los que predominan en los sistemas de salud y jubilaciones. Junto al aprendizaje político de las élites que tienden a integrar el papel del mercado como componente de las políticas sociales y los efectos "candado" generados por las reformas (lock in effect), estos legados contribuyen a consolidar la fragmentación de las políticas sociales aun cuando existen gobiernos que promueven reformas expansivas.

24 Anria \& Niedzwiecki (2016) plantean otro abordaje sobre el papel que desempeña la movilización social en la promoción de la expansión de las políticas sociales en el caso de Bolivia. 
La segunda es la contribución de Pribble (2013) que se ocupa de la dinámica política que guió, no solo a la expansión de la de la protección social hacia la población antes excluida, sino a su universalización. En tal sentido, un aporte de ese trabajo es que concibe el universalismo como un continuo en vez de un concepto dicotómico que incluye cuatro dimensiones: cobertura; transparencia y límites a la discrecionalidad; aumento de la calidad y disminución de la segmentación; y sustentabilidad fiscal (véase también Martínez Franzoni \& Sánchez-Ancochea, 2016b).

Pribble propone un marco explicativo del grado de universalismo de las reformas de las políticas sociales que se basa en tres factores. El principal es el tipo de partido político que está en el gobierno. La presencia de partidos de izquierda es una condición necesaria para la universalización, pero importa también la forma como estos partidos se organizan y vinculan con las bases sociales. El segundo componente de su explicación, al igual que para Garay, es la dinámica de la competencia, pero concentra su atención en el signo ideológico de la misma. El tercer factor, en común con Ewig y Kay, son los legados existentes en cada sector de política social. Estos influyen sobre las perspectivas de la universalización de las políticas sociales, ya que contribuyen a configurar los problemas que se plantean en cada área de política y los principales actores involucrados en la misma (Pribble, 2013, p. 13).

La investigación empírica se centra en las reformas sociales en educación, salud, y asistencia social, realizadas por los gobiernos de centroizquierda de Chile y Uruguay, con un foco secundario en las reformas impulsadas en Argentina y Venezuela. Los resultados de la investigación comparada indican que el tipo de izquierda gobernante — en particular, la programática - junto con la dinámica de la competencia política y los legados sectoriales condujeron a que Chile y Uruguay avanzaran considerablemente hacia la universalización de sus políticas sociales. Mientras tanto, Argentina obtuvo niveles de universalización intermedios y Venezuela no consiguió avances en ese sentido.

En suma, la mayor parte de las contribuciones colocan a la política en el centro del escenario para explicar la dinámica de la expansión 
de las políticas sociales, aunque tienden a concentrarse en un conjunto acotado de países, y solo unas pocas consideran los factores que explican el carácter segmentado de dicho proceso.

\section{Conclusiones}

La revisión de la literatura realizada mostró que los países de América Latina han atravesado por distintas fases en sus regímenes de políticas sociales. En su génesis, establecieron la participación en el mercado formal de empleo como condición para acceder a las políticas sociales contributivas, con lo cual la situación de informalidad pasó a limitar el acceso a la protección social para vastos segmentos de la población. Por consiguiente, desde esa etapa fundacional, los principales ejes de discusión giraron en torno a las limitaciones en la cobertura y a la segmentación de la calidad de la protección social, principalmente a partir de la distinción planteada entre insiders-outsiders.

Con este trasfondo, las tendencias de reformas desplegadas a partir del último cuarto del siglo xx produjeron cambios de signos distintos: i) las reformas neoliberales de los ochenta y los noventa rebajaron los derechos de los insiders, al tiempo que fortalecieron el papel del mercado, creando una nueva fuente de segmentación entre la población protegida; y ii) las reformas de los dos mil comenzaron a expandir la protección social hacia los outsiders mediante la creación o extensión de los beneficios no contributivos que aparecen como una oportunidad para comenzar a resolver las limitaciones de los sistemas de protección social. El diagrama 1 esquematiza los principales ejes divisorios que han atravesado

\section{Diagrama 1. Principales ejes divisorios en los regímenes de políticas sociales en América Latina}

\begin{tabular}{|c|c|c|c|c|c|}
\hline \multicolumn{2}{|c|}{} & \multicolumn{2}{c|}{ Fase neoliberal } & \multicolumn{2}{c|}{$\begin{array}{c}\text { Fase de expansión } \\
\text { segmentada }\end{array}$} \\
\hline Protegidos & Desprotegidos & Protegidos & Desprotegidos & \multicolumn{2}{c|}{ Protegidos } \\
\hline $\begin{array}{c}\text { Formales. } \\
\text { Segmentación } \\
\text { corporativa. }\end{array}$ & Informales. & $\begin{array}{c}\text { Formales. } \\
\text { Segmentación } \\
\text { corporativa y } \\
\text { de mercado. }\end{array}$ & Informales. & $\begin{array}{c}\text { Formales. } \\
\text { Segmentación } \\
\text { corporativa y } \\
\text { de mercado. }\end{array}$ & $\begin{array}{c}\text { Informales. } \\
\text { de menor } \\
\text { calidad. }\end{array}$ \\
\hline
\end{tabular}

Fuente: Elaboración propia. 
a los regímenes de política social y los alcances de la protección social en las tres fases identificadas.

Cada estadio se cristalizó de diferente manera en los grandes grupos de países a lo largo del continente latinoamericano. De hecho, la revisión de la literatura permitió constatar una alta consistencia y estabilidad en los diferentes grupos de países en cada una de las etapas, aun en el contexto de cambios en la estrategia de desarrollo, en la inserción internacional y en los regímenes políticos (Midaglia \& Antía, 2017, p. 62). Esto pone de relieve la importancia de la configuración original de los regímenes de políticas sociales que tuvo consecuencias duraderas sobre sus trayectorias posteriores.

En relación con los determinantes de la orientación y del cambio en los regímenes de política social, la mayor parte de los estudios comparados establece generalizaciones a partir de pocos casos, en particular sobre los países pioneros o los más avanzados. Las explicaciones que dan cuenta de las divergencias en las políticas sociales a nivel regional consideran, fundamentalmente, cuatro grupos de argumentos que subrayan aspectos de tipo: i) económico — los vínculos entre las estrategias de desarrollo y los regímenes de políticas sociales, y los momentos del ciclo económico-; ii) políticos — la democracia, la movilización social, la competencia política, la orientación ideológica de los gobiernos, y los legados de las políticas sociales-; iii) ideacionales; y iv) la influencia externa.

El énfasis en uno u otro aspecto ha variado de acuerdo con la etapa que atravesaron los regímenes de políticas sociales en la región. En la fase fundacional, el foco estuvo en el impacto de la estrategia de desarrollo y las modalidades de incorporación de los trabajadores a la esfera política. La fase de retracción subrayó la importancia de las condiciones económicas, la influencia internacional y los legados de las políticas sociales sobre los procesos de reforma. Por el contrario, durante la reciente etapa expansiva, la atención se centró en aspectos políticos vinculados a la estabilización de la democracia, la ideología de los gobiernos y los legados de las políticas sociales. 
La revisión de la literatura reveló, también, algunas ausencias y agendas no exploradas. En primer lugar, los estudios sobre las políticas sociales se centran en su mayoría en el análisis de las políticas que transfieren bienes o servicios de forma directa. No obstante, los Estados suelen utilizar otros instrumentos, como los tributarios, para desplegar las funciones de la política social (Titmuss, 1958). En otras regiones, estudios como los de Howard (1997) y Goul Andersen y Greve (2016) muestran la importancia del fiscal welfare en términos de los recursos involucrados, impactos distributivos y consecuencias políticas. Sin embargo, esta agenda de investigación no ha sido abordada en los países de América Latina.

Un segundo aspecto que se debe profundizar se refiere a las fuentes de información, sobre todo cuando se compara la literatura sobre los regímenes de políticas sociales en América Latina con la literatura relativa a los países desarrollados. Esta última ha hecho grandes avances a partir del desarrollo de bases de datos que contienen información sobre el diseño institucional de las políticas sociales en múltiples países a lo largo de períodos extensos de tiempo ${ }^{25}$. La creación de este tipo de información, que trasciende los clásicos indicadores de cobertura y gasto, permitiría ahondar en el análisis comparativo de las características, causas y consecuencias de los regímenes de políticas sociales.

En tercer lugar, resta profundizar en el análisis del reciente proceso de "expansión segmentada" que hasta ahora ha sido analizado solo de forma parcial y fragmentaria. En particular, ¿se trata de un cambio de paradigma en los modelos de política social o de ajustes secundarios? ¿Las tipologías existentes son aún apropiadas para caracterizar los regímenes de política social presentes en los países de la región? Por otra parte, ¿qué tan estables y sustentables son los cambios adoptados en las últimas décadas? ¿Están siendo cuestionados por el fin del "giro a la izquierda" y de la holgura económica en varios países? En este nuevo escenario, ¿cuáles son las perspectivas de continuar avanzando en la inclusión de grupos de población aun no cubiertos y en la reducción de los niveles de segmentación de la protección social?

\footnotetext{
25 Véase, por ejemplo, Social Policy Indicators. Recuperado el 23 de septiembre de 2017 de http://www.sofi.su.se/spin
} 
La revisión de la literatura realizada proporciona pistas y posibles respuestas a algunas de estas preguntas, pero revela también la necesidad de realizar nuevos estudios que contribuyan a comprender en profundidad las características y transformaciones de los regímenes de políticas sociales en la región, así como sus consecuencias políticas, económicas y sociales.

\section{Referencias}

Anria, S. \& Niedzwiecki, S. (2016). Social movements and social policy: The Bolivian renta dignidad. Studies in Comparative International Development, 51(3), 308-327. doi: https://doi.org/10.1007/s12116-015-9207-1

Antía, F. (2013). Na direção da moderação da dualização? A reforma recente das politicas sociais em Chile e Uruguai. En F. Gaitán \& A. Del Rio (Eds.), Instituições, política e desenvolvimento: America Latina frente ao século XXI (pp. 267-294). Curitiba: CVR.

Antía, F. \& Lanzara, A. P. (2011). Multi-pillared social insurance systems: The post-reform picture in Chile, Uruguay and Brazil. International Social Security Review, 64(1), 53-71. doi: https://doi.org/10.1111/j.1468246X.2010.01384.x

Antía, F., Rossel, C. \& Manzi, P. (2017, marzo). The politics of conditioning social investment: Evidence from Latin America's cash transfers. Ponencia presentada en el World Politics of Social Investment, París. Recuperado de http://politicsofsocialinvestment.org/

Arza, C. (2008). Pension reform in Latin America: Distributional principles, inequalities and alternative policy options. Journal of Latin American Studies, 40(01), 1-28. doi: https://doi.org/10.1017/S0022216X07003616

Arza, C. (2012). The politics of counter-reform in the Argentine pension system: Actors, political discourse, and policy performance: The politics of counter-reform. International Journal of Social Welfare, 21, S46-S60. doi: https://doi.org/10.1111/j.1468-2397.2012.00872.x

Arza, C. \& Chahbenderian, F. (2014). Programas de transferencias monetarias a las familias: Las experiencias de Argentina, Bolivia, Brasil y Chile. Documentos de Trabajo CIEPP, 90, 1-57.

Avelino, G., Brown, D. S. \& Hunter, W. (2005). The effects of capital mobility, trade openness, and democracy on social spending in Latin America, 
1980-1999. American Journal of Political Science, 49(3), 625-641. doi: https:/ / doi.org/10.1111/j.1540-5907.2005.00146.x

Barba, C. (2007). América Latina: regímenes de bienestar en transición durante los años noventa. Caderno CRH, 20(5), 197-211.

Barba, C. \& Valencia, E. (2015). Diversos universalismos en las trayectorias de las políticas de salud en México y Brasil. Presentado en el Congreso de la Latin American Studies Association, San Juan, Puerto Rico.

Barrientos, A. (2004). Latin America: Towards a liberal-informal welfare regime. En I. Gough \& G. D. Wood (Eds.), Insecurity and Welfare Regimes in Asia, Africa and Latin America (pp. 121-168). Cambridge: Cambridge University Press.

Barrientos, A. (2009). Labour markets and the (hyphenated) welfare regime in Latin America. Economy and Society, 38(1), 87-108. doi: https:/ / doi. org/10.1080/03085140802560553

Bentancur, N. (2008). Las reformas educativas de los años noventa en Argentina, Chile y Uruguay: Racionalidad politica, impactos y legados para la agenda actual. Montevideo: Ed. de la Banda Oriental [u.a.].

Bértola, L. \& Ocampo, J. A. (2010). Desarrollo, vaivenes y desigualdad. Una historia económica de América Latina desde la independencia. Madrid: Secretaría General Iberoamericana.

Blofield, M. \& Martinez Franzoni, J. (2015). Maternalism, co-responsibility, and social equity: A typology of work-family policies. Social Politics: International Studies in Gender, State \& Society, 22(1), 38-59. doi: https:/ / doi.org/10.1093/sp/jxu015

Borzutzky, S. (2002). Vital connections: Politics, social security, and inequality in Chile. Notre Dame: University of Notre Dame Press.

Briggs, A. (2006). The welfare State in historial perspective. En C. Pierson \& F. G. Castles (Eds.), The welfare state reader (2a Ed.) (pp. 16-29). Cambridge: Polity.

Brinks, D. M. \& Forbath, W. (2013). The role of courts and constitutions in the new politics of welfare in Latin America. En R. Peerenboom \& T. Ginsburg (Eds.), Law and Development of Middle-Income Countries (pp. 221-245). New York: Cambridge University Press. doi: https:// doi.org/10.1017/CBO9781139235730.015

Brooks, S. M. (2008). Social protection and the market in Latin America: The transformation of social security institutions. Leiden: Cambridge University 
Press. Recuperado de http://public.eblib.com/choice/publicfullrecord. aspx?p $=412798$

Brooks, S. M. (2015). Social protection for the poorest: The adoption of antipoverty cash transfer programs in the Global South. Politics \& Society, 43(4), 551-582. doi: https://doi.org/10.1177/0032329215602894

Calvo, E., Bertranou, F. M. \& Bertranou, E. (2010). Are old-age pension system reforms moving away from individual retirement accounts in Latin America? Journal of Social Policy, 39(02), 223. doi: https://doi. org/10.1017/S0047279409990663

Campello, D. (2015). The politics of market discipline in Latin America: Globalization and democracy. New York: Cambridge University Press.

Cantu, R. (2015). Depois das reformas: os regimes de proteção social latino -americanos na década de 2000. Revista de Sociologia E Política, 23(56), 45-73. doi: https://doi.org/10.1590/1678-987315235603

Carnes, M. E. \& Mares, I. (2014). Coalitional realignment and the adoption of non-contributory social insurance programmes in Latin America. Socio-Economic Review, 12(4), 695-722. doi: https://doi.org/10.1093/ ser/mwt024

Carnes, M. \& Mares, I. (2015). Explaining the "return of the State" in middle-income countries: Employment vulnerability, income, and preferences for social protection in Latin America. Politics \& Society, 43(4), 525-550. https://doi.org/10.1177/0032329215602893

Castiglioni, R. (2005). The politics of social policy change in Chile and Uruguay: Retrenchment versus maintenance, 1973-1998. New York: Routledge.

Cecchini, S. \& Madariaga, A. (2011). Programas de transferencias condicionadas: Balance de la experiencia reciente en América Latina y el Caribe. Santiago de Chile: CEPAL.

CEPAL. (1996). Quince años de desempeño económico. América Latina y el Caribe 1980-1995. Santiago de Chile: CEPAL.

CEPAL. (2008). Panorama social de América Latina 2007. Santiago de Chile: CEPAL. CEPAL. (2010). La hora de la igualdad: Brechas por cerrar, caminos por abrir. Santiago de Chile: CEPAL.

CEPAL. (2016). Panorama social de América Latina 2015. Santiago de Chile: CEPAL. CEPAL. (2017). Base de datos de programas de protección social no contributiva, División de Desarrollo Social, CEPAL. Recuperado el 24 de mayo de 2017 de http://dds.cepal.org/bdptc/contacto.php 
Collier, R. B. \& Collier, D. (1991). Shaping the political arena: Critical junctures, the labor movement, and regime dynamics in Latin America. Notre Dame: University of Notre Dame Press.

Cominetti, R. \& Ruiz, G. (1998). Evolución del gasto público social en América Latina, 1980-1995. Santiago de Chile: Naciones Unidas, Comisión Económica para América Latina y el Caribe.

Cook, M. L. (2007). Politics of labor reform in Latin America: Between flexibility and rights. University Park: Pennsylvania State University Press.

De la O, A. L. (2015). Crafting policies to end poverty in Latin America: The quiet transformation. New York: Cambridge University Press.

Deacon, B. (2007). Global social policy \& governance. Los Angeles: Sage Publications.

Dion, M. L. (2010). Workers and welfare: Comparative institutional change in twentieth-century Mexico. Pittsburgh: University of Pittsburgh Press.

Draibe, S. \& Riesco, M. (2006). Estado de bienestar, desarrollo económico y ciudadania: Algunas lecciones de la literatura contemporánea. México: CEPAL.

Esping-Andersen, G. (1990). Three worlds of welfare capitalism. Princeton: Princeton University Press.

Esping-Andersen, G. (2000). Fundamentos sociales de las economías postindustriales. Barcelona: Ariel.

Evans, P. B. \& Sewell, W. H. (2013). Neoliberalism. En P. A. Hall \& M. Lamont (Eds.), Social resilience in the neo-liberal era (pp. 35-68). Cambridge: Cambridge University Press. doi: https://doi.org/10.1017/ CBO9781139542425.005

Ewig, C. (2010). Second-wave neoliberalism: Gender, race, and health sector reform in Peru. University Park: Pennsylvania State University Press.

Ewig, C. \& Kay, S. J. (2011). Postretrenchment politics: Policy feedback in Chile's health and pension reforms. Latin American Politics and Society, 53(4), 67-99. doi: https://doi.org/10.1111/j.1548-2456.2011.00134.x

Ezcurra, A. M. (1996). Banco Mundial y fondos sociales en América Latina y el Caribe. Recuperado de http:// escotet.org/iidev/forum/ professional-papers/banco-mundial-y-fondos-sociales-en-americalatina-y-el-caribe/

Fairfield, T. \& Garay, C. (2017). Redistribution under the right in Latin America: Electoral competition and organized actors in policymaking. Comparative Political Studies, 50(14), 1871-1906. doi: https:/ / doi. org/10.1177/0010414017695331 
Ferrera, M. (1996). The "Southern model" of welfare in social Europe. Journal of European Social Policy, 6(1), 17-37. doi: https://doi. org/10.1177/095892879600600102

Filgueira, F. (1998). El nuevo modelo de prestaciones sociales en América Latina; residualismo y ciudadanía estratificada. En B. Roberts (Ed.), Ciudadanía y politica social (pp. 71-116). San José, Costa Rica: FLACSO/sSRC.

Filgueira, F. (2005). Welfare and democracy in Latin America: The development, crises and aftermath of universal, dual and exclusionary social States. Preparado para el proyecto en política social y democratización, UNRISD. Recuperado de http://www.unrisd. org/80256B3C005BCCF9/(httpPublications)/D1F612F7B7D71534C1256FFF005447F7

Filgueira, F. (2007). Past, present and future of the Latin American social State: Critical junctures and critical choices. Serie Documentos de Trabajo Del IPES / Colección Estudios Comparados, 7, 1-34.

Filgueira, F. (2013). Los regímenes de bienestar en el ocaso de la modernización conservadora: Posibilidades y límites de la ciudadanía social en América Latina. Revista Uruguaya de Ciencia Política, 22(2), 17-46.

Filgueira, F. (2015). Modelos de desarrollo, matriz del Estado social y herramientas de las políticas sociales latinoamericanas. En S. Cecchini (Ed.), Instrumentos de protección social: Caminos latinoamericanos hacia la universalización (pp. 49-126). Santiago de Chile: Naciones Unidas, CEPAL.

Fiszbein, A., Schady, N., Ferreira, F. H. G., Grosh, M., Keleher, N., Olinto, P. \& Skoufias, E. (Eds.). (2009). Conditional cash transfers: Reducing present and future poverty. Washington D. C.: World Bank.

Fleury, S. (1999). Política social, exclusión y equidad en América Latina en los años noventa, Documentos no 15 , Centro de Documentación en Políticas Sociales, Buenos Aires. Documentos, 15.

Franco, R. (1996). Los paradigmas de la política social en América Latina. Revista de la CEPAL, 58, 9-22.

Gajardo, M. (1999). Reformas educativas en América Latina: Balance de una década. Santiago de Chile: PREAL.

Garay, C. (2007). Social policy and collective action: Unemployed workers, community associations, and protest in Argentina. Politics \& Society, 35(2), 301-328. doi: https://doi.org/10.1177/0032329207300392

Garay, C. (2016). Socialpolicy expansion in Latin America. New York: Cambridge University Press. 
Gauri, V. \& Brinks, D. M. (2010). Courting social justice: judicial enforcement of social and economic rights in the developing world. New York: Cambridge University Press.

Gough, I. (2000). Welfare regimes: On adapting the framework to developing countries. Global Social Policy Program, Institute for International Policy Analysis, University of Bath. Recuperado de http:/ /www.bath. ac.uk/Faculties/HumSocSci/IFIPA/GSP/

Gough, I. (2004). Welfare regimes in development contexts: A global and regional analysis. En I. Gough \& G. D. Wood (Eds.), Insecurity and welfare regimes in Asia, Africa and Latin America (pp. 15-48). Cambridge: Cambridge University Press.

Gough, I. \& Wood, G. D. (2004). Insecurity and welfare regimes in Asia, Africa and Latin America. Cambridge: Cambridge University Press.

Goul Andersen, J. \& Greve, B. (2016). Phasing out fiscal welfare: The Danish case. Presentado en el Fiscal Welfare, París.

Haggard, S. \& Kaufman, R. R. (2008). Development, democracy and welfare states: Latin America, East Asia, and Eastern Europe. Princeton: Princeton University Press.

Hardy, C. (2011). De la pobreza a la desigualdad. Políticas sociales post crisis. Presentado en la IV Conferencia Ministerial de Desarrollo, Santiago de Chile.

Hirschman, A. (1968). La economía política de la industrialización a través de la sustitución de importaciones en América Latina. El Trimestre Económico, 35(140), 625-658.

Holliday, I. (2000). Productivist welfare capitalism: Social policy in East Asia. Political Studies, 48(4), 706-723. doi: https://doi.org/10.1111/14679248.00279

Howard, C. (1997). The bidden welfare state: Tax expenditures and social policy in the United States. Princeton: Princeton University Press.

Huber, E. (1996). Options for social policy in Latin America: Neoliberal versus social democratic models. En G. Esping-Andersen (Ed.), Welfare states in transition: National adaptations in global economies (pp. 141-192). London: Sage.

Huber, E. \& Stephens, J. D. (2012). Democracy and the left: Social policy and inequality in Latin America. Chicago: The University of Chicago Press.

Isuani, E. A. (1985). Los orígenes conflictivos de la seguridad social argentina. Buenos Aires: Centro Editor de América Latina. 
Itzcovich, G. (2013). La expansión educativa en el nivel inicial durante la última década. Cuaderno SITEAL 16, International Institute for Educational Planning, Paris.

Kaufman, R. R. \& Nelson, J. M. (Eds.). (2004). Crucial needs, weak incentives: Social sector reform, democratization, and globalization in Latin America. Washington, D. C.; Baltimore: Woodrow Wilson Center Press; Johns Hopkins University Press.

Kay, S. J. (1999). Unexpected privatizations: Politics and social security reform in the Southern Cone. Comparative Politics, 31(4), 403-422.

Kaztman, R. (2002). Convergencia y divergencias: Exploración sobre los efectos de las nuevas modalidades de crecimiento sobre la estructura social de cuatro áreas metropolitanas. En R. Kaztman \& G. Wormald (Eds.), Trabajo y ciudadanía. Los cambiantes rostros de la integración y exclusión social en cuatro áreas metropolitanas de América Latina (pp. 23-59). Montevideo: Editorial Universidad Católica.

Krennerich, M. \& Góngora Mera, M. E. (2006). Los derechos sociales en América Latina: Desafíos en justicia, política y economía. Nuremberg: NMRZ.

Larrañaga, O. (2010). Las nuevas politicas de protección social en perspectiva histórica. Santiago de Chile: Programa de las Naciones Unidas para el Desarrollo.

Levitsky, S. \& Roberts, K. M. (Eds.). (2011). The resurgence of the Latin American left (1a Ed.). Baltimore Johns Hopkins University Press: Ann Arbor, Michigan.

Lindert, K., Skoufias, E. \& Shapiro, J. (2006). Redistributing income to the poor and the rich: Public transfers in Latin America and the Caribbean. (No. 91). Washington D. C.: World Bank. Recuperado de http://documents. worldbank.org/curated/en/534671468044934128/Redistributingincome-to-the-poor-and-the-rich-public-transfers-in-Latin-Americaand-the-Caribbean

Madrid, R. L. (2003). Retiring the state: The politics of pension privatization in Latin America and beyond. Stanford: Stanford University Press.

Malloy, J. M. (1979). The politics of social security in Brazil. Pittsburgh: University of Pittsburgh Press. Recuperado de http://digital.library.pitt.edu/ cgi-bin $/ \mathrm{t} /$ text $/$ text-idx?idno $=31735057895652 ;$ view $=$ toc; $c=$ pittpress

Mares, I. \& Carnes, M. E. (2009). Social policy in developing countries. Annual Review of Political Science, 12(1), 93-113. doi: https://doi. org/10.1146/annurev.polisci.12.071207.093504 
Martínez Franzoni, J. (2008). Domesticar la incertidumbre en América Latina. Mercado laboral, política social y familias. San José: Universidad de Costa Rica.

Martínez Franzoni, J. \& Sánchez-Ancochea, D. (2013a). Good jobs and social services: How Costa Rica achieved the elusive double incorporation. Houndmills: Palgrave Macmillan.

Martínez Franzoni, J. \& Sánchez-Ancochea, D. (2013b). Should policy aim at having all people on the same boat? The definition, relevance and challenges of universalism in Latin America. DesiguALdades.net Working Paper Series, 70.

Martínez Franzoni, J. \& Sánchez-Ancochea, D. (2016a). Regímenes de bienestar en América Latina: Tensiones entre universalización y segmentación. En E. Del Pino \& M. J. Rubio (Eds.), Los Estados de bienestar en la encrucijada: Políticas sociales en perspectiva comparada (pp. 200-218). Madrid: Tecnos.

Martínez Franzoni, J. \& Sánchez-Ancochea, D. (2016b). The quest for universal social policy in the South: Actors, ideas and architectures. New York: Cambridge University Press.

Mesa-Lago, C. (1979). Social Security in Latin America: Pressure Groups, Stratification and Inequality. Pittsburgh: University of Pittsburgh Press.

Mesa-Lago, C. (1986). Seguridad social y desarrollo en América Latina. Revista de la CEPAL, 28, 131-146.

Mesa-Lago, C. (2008). Reassembling social security: A survey of pensions and bealth care reforms in Latin America (1a Ed.). Oxford: Oxford University Press.

Meseguer, C. (2009). Learning, policy making, and market reforms. Cambridge: Cambridge University Press, primera edición de bolsillo.

Midaglia, C. \& Antía, F. (2017). Bienestar y protección social en América Latina. Abordajes conceptuales y metodológicos para el MERCOSUR. Asunción: Instituto MERCOSUR Social.

Molina, C. G. (2006). Universalismo básico: Una nueva política socialpara América Latina. Washington, D. C.: Inter-American Development Bank.

Moreno, L. (2002). Spanish development of Southern European welfare. En S. Kuhnle (Ed.), Survival of the European Welfare State (pp. 146-165). London: Routledge.

Noguera Fernández, A. (2010). Los derechos sociales en las nuevas constituciones latinoamericanas. Valencia: Editorial Tirant lo Blanch.

OIT. (2000). Panorama laboral 2000. Perú: OIT. 
OIT. (2011). Piso de protección social para una globalización equitativa e inclusiva: Informe del grupo consultivo presidido por Michelle Bachelet convocado por la OIT con la colaboración de la OMS. Ginebra: OIT.

Orszag, P. \& Stiglitz, J. (2001). Rethinking pension reform: Ten myths about social security systems. En R. Holzmann \& J. Stiglitz (Eds.), New Ideas about Old Age Security: Toward Sustainable Pension Systems in the 21 st Century (pp. 17-56). Washington, D. C.: World Bank.

Papadópulos, J. (1992). Seguridad social y política en el Uruguay. Montevideo: CIESU.

Pribble, J. (2011). Worlds apart: Social policy regimes in Latin America. Studies in Comparative International Development, 46(2), 191-216. doi: https://doi.org/10.1007/s12116-010-9076-6

Pribble, J. (2013). Welfare and party politics in Latin America (1a Ed.). Cambridge: Cambridge University Press.

Rodríguez Garavito, C. (2011). Beyond the courtroom: The impact of judicial activism on socioeconomic rights in Latin America. Texas Law Review, 89(7), 1669-1698.

Rofman, R., Apella, I. \& Vezza, E. (2015). Beyond contributory pensions: Fourteen experiences with coverage expansion in Latin America. Washington, D. C.: World Bank.

Rossi, F. M. (2015). The second wave of incorporation in Latin America: A conceptualization of the quest for inclusion applied to Argentina. Latin American Politics and Society, 57(1), 1-28. doi: https://doi. org/10.1111/j.1548-2456.2015.00256.x

Rudra, N. (2008). Globalization and the race to the bottom in developing countries: Who really gets hurt? Leiden: Cambridge University Press. Recuperado de http://public.eblib.com/choice/publicfullrecord.aspx?p=367088

Santos, W. G. (1979). Cidadania e justiça: a política social na ordem brasileira. Rio de Janeiro: Editora Campus.

Segura-Ubiergo, A. (2007). The political economy of the welfare state in Latin America: Globalization, democracy, and development. Cambridge: Cambridge University Press. Recuperado de http:/ / site.ebrary.com/id/10182286

Silva, E. (2017). Reorganizing popular sector incorporation: Propositions from Bolivia, Ecuador, and Venezuela. Politics \& Society, 45(1), 91-122. doi: https://doi.org/10.1177/0032329216683166

Stallings, B. (1992). International influence on economic policy, debt stabilization, and structural reform. En S. Haggard \& R. R. Kaufman (Eds.), 
The Politics of Economic Adjustment: International Constraints, Distributive Conflicts and the State (pp. 41-88). Princeton: Princeton University Press. Sugiyama, N. B. (2011). The diffusion of conditional cash transfer programs in the Americas. Global Social Policy, 11(2-3), 250-278. doi: https:// doi.org/10.1177/1468018111421295

Titmuss, R. M. (1958). Essays on the welfare State. London: Allen \& Unwin. Weyland, K. G. (2006). Bounded rationality and policy diffusion: Social sector reform in Latin America. Princeton: Princeton University Press.

Wilensky, H. L. (1975). The welfare State and equality: Structural and ideological roots of public expenditure. Berkeley: University of California Press.

Williamson, J. (1990). What Washington means by policy reform. En Latin American Adjustment: How Much Has Happened? (pp. 5-20). Washington, D. C.: Institute for International Economics. 
